\title{
COMMUNITY REINFORCEMENT AND FAMILY TRAINING (CRAFT): Engaging Unmotivated Drug Users in Treatment
}

\author{
ROBERT J. MEYERS* \\ WILLIAM R. MILLER \\ DINA E. HILL \\ J. SCOTT TONIGAN \\ Center on Alcoholism, Substance Abuse, and Addictions \\ (CASAA), University of New Mexico, Albuquerque, NM, USA
}

\begin{abstract}
Although motivation for drug abuse treatment is a substantial problem, unilateral intervention through concerned significant others (CSOs) represents a promising method for engaging unmotivated individuals. The Community Reinforcement and Family Training (CRAFT) program, based on principles of reinforcement, was developed for this specific purpose. In Phase I, CSOs received the CRAFT intervention, whereby they were taught skills for modifying a loved one's drug-using behavior and for enhancing treatment engagement. CSOs were evaluated at 3 and 6 months. In Phase II, engaged drug users received treatment using the Community Reinforcement Approach (CRA). A total of 62 CSOs participated in this evaluation of the effectiveness of CRAFT. CSOs completed, on average, $87 \%$ of offered treatment sessions. During the 6-month study period, 74\% succeeded in engaging their resistant loved one in treatment. Reported abstinence both from illicit drugs and alcohol increased significantly for drug users engaged in treatment, but not for unengaged cases. All CSOs showed significant reductions in depression, anxiety, anger, and physical symptoms, with average scores dropping into the normal range on all measures. CRAFT provides a promising alternative to confrontational and detachment approaches in counseling CSOs to help their loved ones.
\end{abstract}

*Direct all correspondence to: Robert J. Meyers, Center on Alcoholism, Substance Abuse, and Addictions (CASAA),2350 Alamo SE, Albuquerque,New Mexico,87106; E-mail: bmeyers@unm.edu

JOURNAL OF SUBSTANCE ABUSE, Volume 10, Number 3, pages 291-308.

Copyright $(1999$ by Elsevier Science Inc.

All rights of reproduction in any form reserved.

ISSN: 0899-3289 


\section{INTRODUCTION}

It is not unusual for individuals with drug problems to be unmotivated for treatment. The Institute of Medicine (1990) observed that "the nature and success of drug treatment is complicated by the typical reluctance of dependent and abusing individuals to seek treatment or stay in it" (p. 9). Prochaska and his colleagues have estimated that over $80 \%$ of individuals with addictive behavior problems are in the precontemplation or contemplation stage (e.g., Snow et al., 1992), not ready to take steps toward change. Early treatment is important, however, because individuals who seek help at earlier stages of drug dependence often experience more favorable outcomes (e.g., McLellan et al., 1983).

Substance abuse facilities regularly receive calls from desperate friends and family members seeking advice regarding the drug problems of a loved one who is unmotivated for change. Historically, there have been few options for such individuals seeking help for their treatment-resistant loved ones. Foote et al. (1985) observed that $85 \%$ of the individuals contacting their drug abuse treatment center "... could not be helped because they never entered therapy. Typically, one concerned family member would contact the center but would be unable to convince the rest of the family to enter therapy" (p. 63). Further, even when drug-dependent individuals contact a treatment system, early dropout is a significant problem (Kleinman et al., 1990). Ellis et al. (1992) found that the modal number of sessions completed by people presenting for drug abuse treatment in New Mexico was one.

Various untested counseling approaches for concerned significant others (CSOs) have been advocated, evolving from disparate understandings of the nature of motivation and drug problems, and in some cases leading to diametrically opposed recommendations. One approach, arising from the spiritual 12-step program (Al-Anon Family Groups, 1984), advocates loving detachment, acceptance of the CSO's powerlessness to change the problem, and group support for the CSO. A rather different tradition is direct confrontation of the user, historically rooted not in 12-step approaches but in Synanon and psychodynamic thinking that emphasize virulent defense mechanisms (Miller and Kurtz, 1994). A familiar U.S. manifestation of this approach is the intervention developed by Johnson (1986), in which CSOs plan a confrontational meeting to engender treatment-seeking.

Unilateral family therapy represents a third approach, in which CSOs are taught skills and strategies for altering a loved one's behavior and for motivating change (Thomas and Santa, 1982; Thomas et al., 1990). Thomas et al. (1987) assigned spouses of alcoholics to receive either immediate or delayed treatment, and followed 10 other untreated nonrandom comparison subjects (apparently treatment drop-outs). Of the 13 (of 15) treated cases with usable data at 4-6 month follow-up, eight alcoholics $(62 \%)$ had entered treatment or reduced drinking by at least $53 \%$ or both, whereas none of the six (of 10 ) comparison cases found at follow-up had done so.

The feasibility of altering a drug-involved family system through one member has also been demonstrated by Szapocznik and his colleagues who, in a randomized trial with 37 Hispanic families of drug-abusing adolescents, compared brief strategic therapy delivered to all family members or primarily to one member (Szapocznik et al., 1983, 1986). At follow-ups to 12 months, comparable changes were observed in family interactions/ structure and in symptomatology of the identified patient (IP). 
Surprisingly little evaluation research has been directed to the effectiveness of these three rather different CSO counseling strategies. Studies to date have been hindered by small sample sizes, limited outcome measures, and the lack of a clear theoretical rationale for intervention (e.g. Dittrich and Trapold, 1984; Liepman et al., 1989). The impact of such interventions on drug-dependent individuals, on CSOs, and on their relationships is virtually unknown. To our knowledge, the only controlled evaluation to date of a strategy for counseling CSOs of drug-dependent individuals is that of Szapocznik et al. (1983, 1988), whose research focused on adolescents, and who conducted unilateral family interventions through the drug abuser. Family-engaged strategies more generally have shown promise once drug abusers are in treatment (Stanton and Todd, 1982; Kaufman, 1985; Kaufman and Kaufman, 1992), and a parallel literature shows substantial benefit from the inclusion of CSOs in the treatment of alcoholism (McCrady, 1989; O'Farrell, 1993). Research on posttreatment trajectories also indicates that family and social support play a key role in the maintenance of outcomes (Moos et al., 1990; Constantini et al., 1992). These findings indicate that, from an operant perspective, CSOs are not powerless but have access to modifiable contingencies capable of altering the course of drug dependence.

Interventions with CSOs have typically lacked a theoretical base. There is a need to build an empirical and theoretical foundation for the treatment of drug problems (Institute of Medicine, 1990). Operant psychology offers a coherent and well-tested theoretical basis for conceptualizing and addressing drug dependence (Griffiths et al., 1980). Both animal (Bickel et al., 1990; Balster, 1991; Carroll et al., 1991) and human studies (Hursh, 1991; Bickel et al., 1992, 1995) amply demonstrate the responsiveness of drug-taking behavior to reinforcement contingencies. Therapeutic strategies derived from an operant model have already shown promise in treating drug problems (Stitzer et al., 1979; Miller and Hester, 1986; Higgins et al., 1991; Stitzer and Kirby, 1991; Bickel et al., 1995), and more generally as family therapy interventions (Azrin et al., 1973; Patterson, 1982). The Community Reinforcement Approach (CRA) was explicitly developed as an application of operant theory to the treatment of alcoholism (Hunt and Azrin, 1973; Azrin et al., 1982; Sisson and Azrin, 1986). In a series of clinical trials, CRA has been found to be differentially effective in the treatment of alcoholism (Hunt and Azrin, 1973; Azrin 1976; Azrin et al., 1982; Mallams et al., 1982), a promising treatment for cocaine dependence (Higgins, 1996; Higgins et al., 1991, 1994), and an effective treatment for opioid addicts on methadone maintenance (Abbott et al., 1998). One study found the CRA approach to be particularly effective with those individuals who did not have a stable marital relationship (Azrin et al., 1982).

Sisson and Azrin (1986) introduced a unilateral family approach grounded in operant theory, in which CSOs were taught to modify contingencies over which they had control, and that could maintain or suppress alcoholic drinking. Their approach included procedures for rapidly engaging the individual with alcoholism in treatment once a critical mass of motivation was achieved. Sisson and Azrin (1986) randomly assigned 12 CSOs to receive either this Community Reinforcement Training (CRT) approach or a disease model/Al-Anon counseling approach. In the CRA, six of seven alcoholics entered treatment after a mean of 58.2 days and an average of 7.2 sessions. Further, they had already reduced their mean consumption by more than half at the point of initiating treatment. In the comparison group, none of five who entered treatment 
evidenced improvement; a close parallel to the above-discussed findings of Thomas et al. (1987).

This report describes the development and initial testing of a CSO counseling strategy specifically designed to address drug problems in adults. Various research designs can be used to evaluate the impact of behavioral interventions, and the optimal design depends on the stage of therapy development and the specific questions to be asked (Kazdin, 1994). At early stages of development, the single-subject and small sample designs are often used to refine the treatment approach. Once treatment procedures have been standardized, an uncontrolled single-group design is often used to study the magnitude of pre-post change and variability in client response. If results appear promising at this level, a formal randomized trial is an appropriate next step. This study represents the middle step in development and evaluation of a new treatment: a larger $(N=62)$ single group evaluation, which led to a randomized trial that is currently underway.

A modified and updated Community Reinforcement and Family Training (CRAFT) approach was designed to engage adult drug users in treatment through unilateral family therapy with one or more CSOs (Meyers and Smith, 1997, Meyers, Smith, and Miller, 1998; Meyers et al., 1996). To ensure the consistent availability of care for the resistant drug abuser successfully motivated by CSOs (in Phase I) to enter treatment, the project also offered a Phase II cognitive-behavior therapy for drug abuse combining motivational enhancement therapy (Miller et al., 1992) and community reinforcement strategies (Meyers and Smith, 1995). It was hypothesized that there would be significant improvement from baseline through follow-ups in three areas: CSO functioning, IP functioning, and CSO and IP relationship.

\section{METHODS}

\section{Study Sample}

Clients for Phase I were 62 CSOs seeking help with regard to known drug problems of a loved one. Announcements were made through public news media of a free program for those concerned about a loved one with drug problems who was resistant to getting help. A total of 303 individuals called the project telephone number to inquire about the study. Of these, 196 were determined to be uninterested, inappropriate, or ineligible for the study and were referred to community resources. The remaining 107 were scheduled for a diagnostic screening interview, of whom 62 kept the appointment, met inclusion criteria, agreed to participate in the study, and completed intake assessment. Fifty-five percent of the total sample was recruited from local newspaper advertisements, with the remaining $45 \%$ recruited from radio advertisements, pamphlets distributed in medical settings, and by word of mouth.

To be eligible for the project, CSOs must have had sufficient contact (36 out of the past 90 days) with an IP who was a first degree relative (e.g., parent, child, sibling) or a marital spouse or unmarried intimate partner. Both the CSO and the IP were 18 years or older and lived within 60 miles of the treatment site. By CSO report, IPs met criteria for a primary diagnosis of drug abuse or dependence, and had not received treatment in the past 3 months. CSOs did not meet the criteria for dependence or abuse of any substance. Neither the CSO nor the IP met criteria for psychosis. Finally, CSOs 
were willing to participate in the study and had at least a sixth grade reading comprehension level.

CSOs passing prescreening criteria were scheduled for a diagnostic screening interview, during which the interviewer (usually the first author) reviewed the nature and conditions of the study, completed a formal review of the elements of informed consent, obtained CSO consent, and then proceeded to administer screening instruments to determine formal eligibility. Eligible CSOs then proceeded into intake assessment often immediately following diagnostic screening or by appointment soon thereafter.

\section{Phase I and II Therapist Training and Supervision}

Therapists worked in either Phase I with CSOs or Phase II with IPs. The five Phase I therapists included a psychologist with 20 years of clinical practice, several masters level therapists with relatively little experience, and one bachelor's level therapist with several years of substance abuse treatment experience, including previous experience in providing CRAFT procedures. The therapists were two males and three females, of whom two were Hispanic and three non-Hispanic. Four other non-Hispanic therapists ( 2 males, 2 females) conducted Phase II treatment of IPs. Two held a Ph.D. in clinical psychology and two were masters level therapists. Phase II therapists had more overall treatment experience than did the Phase I therapists. Phase I and II therapists received approximately $20 \mathrm{~h}$ of training prior to contact with clients. Training was provided for each particular protocol and therapists were given detailed manuals to guide treatment. Ongoing weekly supervision was provided separately for each protocol (Phase I and Phase II) and included reviewing videotapes of treatment sessions.

\section{Phase I Intake and Follow-up Assessments}

In Phase I, CSOs were of necessity the only data sources for all cases, because not all IPs sought treatment and entered Phase II. Therefore, we obtained data from CSOs regarding all three domains of anticipated impact: CSO status, IP status, and relationship status. The total Phase I intake battery required about $4.5 \mathrm{~h}$ to complete. The intake assessment battery for CSOs is outlined in Table 1. Follow-up interviews were conducted with the $\mathrm{CSO}$ at 3- and 6-month intervals after Phase I initiation. The follow-up assessment battery mirrored the baseline assessment (see Table 1). Additionally, the Form 90-DI\&F (Miller, 1996) were used to construct a continuous time line of drug use throughout the 6-month period for both IP and CSO.

\section{Phase I Intervention}

Phase I intervention directly replicated the approach developed by the first author, and evaluated by Sisson and Azrin (1986). In this CRAFT approach, CSOs are told that they can have a substantial impact on the IP's drug use and decision to enter treatment, and are taught skills for doing so (Meyers and Smith, 1997; Meyers et al., 1996). Specific components of this intervention include: (1) raising awareness of negative consequences caused by the IP's drug use and possible personal benefits of treatment; (2) learning specific strategies for preventing dangerous situations; (3) 
TABLE 1

Instrument Administered at Assessment Points in Phase I (CSO's) and Phase II (IPs)

\begin{tabular}{|c|c|c|c|c|c|}
\hline & & Phase I & & Phas & II (IP) \\
\hline & $\ln ^{a}$ & 3 Months & 6 Months & $\ln ^{a}$ & $F U^{b}$ \\
\hline Approximate Total Testing Hours & 4.5 & & 3 & 3 & 2 \\
\hline Participant Fee Payment & 0 & $\$ 100$ & $\$ 60$ & $\$ 60$ & $\$ 60$ \\
\hline Interviewer-Administered & & & & & \\
\hline SCID alcohol/drug/psychosis & OS & & & & \\
\hline Addiction severity index & & & & $\mathrm{S}$ & \\
\hline Urine drug screen & & & & $\mathrm{S}$ & $\mathrm{S}$ \\
\hline Family history interview & $\mathrm{S}$ & & & & \\
\hline Demographics & $\mathrm{S}$ & & & $\mathrm{S}$ & \\
\hline Lifetime treatment history & OS & & & $\mathrm{S}$ & \\
\hline Form 90-DC & $\mathrm{O}$ & $\mathrm{O}$ & $\mathrm{O}$ & & \\
\hline Form 90-DI & $\mathrm{S}$ & & & $\mathrm{S}$ & \\
\hline Form 90-DF & & $\mathrm{S}$ & $\mathrm{S}$ & & $\mathrm{S}$ \\
\hline Conflict tactic scale & $\mathrm{R}$ & $\mathrm{R}$ & $\mathrm{R}$ & $\mathrm{R}$ & $\mathrm{R}$ \\
\hline Socrates & $\mathrm{O}$ & & & $\mathrm{S}$ & \\
\hline Marin short-form scale & $\mathrm{S}$ & & & & \\
\hline Oetting and Beuvais scale & $\mathrm{S}$ & & & & \\
\hline Beck depression inventory & $\mathrm{S}$ & $\mathrm{S}$ & $\mathrm{S}$ & $\mathrm{S}$ & $\mathrm{S}$ \\
\hline State/trait anxiety inventory & $\mathrm{S}$ & $\mathrm{S}$ & $\mathrm{S}$ & & \\
\hline State/trait anger inventory & $\mathrm{S}$ & $\mathrm{S}$ & $\mathrm{S}$ & & \\
\hline State self-esteem scale & $\mathrm{S}$ & $\mathrm{S}$ & $\mathrm{S}$ & & \\
\hline Physical symptoms scale & $\mathrm{S}$ & $\mathrm{S}$ & $\mathrm{S}$ & & \\
\hline Purpose in life scale & $\mathrm{S}$ & & $\mathrm{S}$ & & \\
\hline Locus of control scale & $\mathrm{S}$ & & & & \\
\hline InDUC (drug consequences) & & & & $\mathrm{S}$ & $\mathrm{S}$ \\
\hline InDUC-SO & $\mathrm{O}$ & $\mathrm{O}$ & $\mathrm{O}$ & & \\
\hline 12-Step involvement questionnaire & $\mathrm{S}$ & $\mathrm{S}$ & $\mathrm{S}$ & $\mathrm{S}$ & $\mathrm{S}$ \\
\hline Self-efficacy ratings & $\mathrm{S}$ & $\mathrm{S}$ & $\mathrm{S}$ & & \\
\hline Social functioning and resources & $\mathrm{S}$ & $\mathrm{S}$ & $\mathrm{S}$ & & \\
\hline Family environment scale & $\mathrm{R}$ & $\mathrm{R}$ & $\mathrm{R}$ & $\mathrm{R}$ & $\mathrm{R}$ \\
\hline Dyadic adjustment scale & $\mathrm{R}$ & $\mathrm{R}$ & $\mathrm{R}$ & $\mathrm{R}$ & $\mathrm{R}$ \\
\hline Relationship happiness scale & $\mathrm{R}$ & $\mathrm{R}$ & $\mathrm{R}$ & $\mathrm{R}$ & $\mathrm{R}$ \\
\hline
\end{tabular}

Notes. a. Intake (baseline) assessment.

b. Measures used at follow-up for IPs.

$\mathrm{S}=$ Self-report, $\mathrm{O}=\mathrm{CSO}$ 's report of IP status, $\mathrm{R}=$ Report of CSO/IP relationship status

contingency management training to reinforce the IP's non-using behaviors and to extinguish drug use; (4) social skill training to improve relationship communication and problem-solving skills; (5) planning of activities that interfere and compete with the IP's drug use; (6) practicing strategies to interfere with actual and potential IP's drug use; and (7) preparing to initiate treatment when the IP appears ready, and supporting the IP once treatment has begun. Other adaptive skills are taught to improve the life quality of the CSO, such as increasing the CSO's own reinforcing activities outside the relationship. The maximum length of Phase I CRAFT was set at 6 months or 12 sessions, with two additional emergency sessions at the therapist's discretion. A structured therapist manual was developed to provide clear specifications and guidelines for the delivery of treatment procedures. Because family violence is a high risk in 
this population (Miller, 1990), all CSOs were counseled early in strategies for preventing and coping with violence-risk situations.

\section{Phase II Intake Assessment and Follow-up}

Starting from the CSO's first treatment session, a window of 6 months was allowed during which the IP could enter Phase II treatment. CSOs were given a rapid-access pager number to call when their IP was willing to consider treatment. When such calls were received, IPs were scheduled for consultation within $48 \mathrm{~h}$. At this appointment, a clinical research staff member described to the IP: (1) the rapid availability of free treatment through the trial, and of alternative treatment programs in the community; (2) Phase II study conditions; and (3) the conditions of informed consent. No additional exclusion criteria were used at this point, as all IPs referred from Phase I were eligible for Phase II. If the IP provided signed consent, a 3-h pretreatment evaluation was completed. The principal components of this assessment are listed in Table 1. A Phase II follow-up was conducted at 3 months following the first treatment session for engaged IPs.

\section{Phase II Treatment}

Upon completion of the assessment, a first treatment session was scheduled with the IP. Phase II treatment began with Motivational Enhancement Therapy (MET: two to four sessions), which is designed to strengthen the IP's intrinsic motivation and commitment to change. Personal assessment results were given as motivational feedback, which have been shown in a series of randomized trials to suppress substance use (Miller et al., 1988, 1993; Bien et al., 1993; Brown and Miller, 1993; Saunders et al., 1995). From this point onward, Phase II therapists followed CRA treatment strategies (8-11 sessions) using both a standard set of core procedures and a menu of optional treatment modules matched to clients' needs (Meyers and Smith, 1995). The core procedures included: (1) a functional analysis of the IP's drug use; (2) the development of treatment goals; (3) sobriety sampling; (4) drug refusal training; (5) social skills training including communication skills and problem-solving skills; (6) social and recreation counseling; and (7) relapse prevention training. Treatment was again capped at a maximum of 6 months or 12 sessions plus two discretionary emergency sessions, whichever came first.

Since the mean number of sessions attended by the CSOs was 10.5 , they attended about five sessions after the IP entered treatment. It is our belief that CRAFT therapists' efforts to help the CSO learn new strategies and skills to promote abstinence probably contributed to the high IP retention rates. This is based, in part, on the fact that only eight IPs utilized couples therapy, with six of them attending just one couples session. So it appears that much of the CSOs' assistance with their IPs came through the CSOs' own therapy.

\section{RESULTS}

\section{Sample Characteristics}

The 62 Phase I study participants ranged in age from 18 to $73(M=44.7$ years), and 60 (97\%) were women. Ethnic self-identification was as follows: 30 (48\%) Hispanic, 29 
(47\%) white non-Hispanic, 2 (3\%) Native American, and 1 (2\%) African American. Although the project was originally designed anticipating spouses, the presenting CSOs were more often parents (33 mothers and 2 fathers), 56\%; 21 (34\%) were spouses, $4(6 \%)$ were siblings, and $2(4 \%)$ were children.

The IPs about whom CSOs were concerned ranged in age from 18 to $51(M=29.8)$, and $77 \%$ were men. By the report of CSOs whose IP entered treatment (44 CSOs), the primary drug of concern was most often cocaine (39\%), followed by stimulants $(29 \%)$, marijuana (18\%), opiates $(9 \%)$, and other drug types $(5 \%)$. When IPs entered Phase II, however, we found that their self-report of the primary drug of abuse sometimes differed from that reported by the CSO. By self-report (44 IPs), the engaged IPs' primary drugs of abuse were marijuana $(43 \%)$, cocaine $(32 \%)$, stimulants $(14 \%)$, opiates $(9 \%)$, and tranquilizers $(2 \%)$.

\section{CSO and IP Engagement in Treatment}

Of the 62 CSOs who completed intake assessment and were admitted to the study, all 62 returned to begin treatment. The average number of sessions (out of 12) completed by CSOs was 10.45 (87\%), and of those who completed all 12 sessions (41, $62 \%$ ), many expressed a desire to continue. Of the 62 CSOs who entered Phase I, 46 (74\%) succeeded in engaging their IP in Phase II treatment within 6 months. Two of these IPs sought treatment at facilities other than Phase II treatment. The average length of CSO counseling before Phase II engagement was 4.84 sessions (range: 0-12) or 6.43 weeks (range: $0-24$ ). Two other IPs agreed to enter Phase II treatment, but did so after the 6-month window of eligibility, one only a few days and the other several months late, raising the engagement rate to $77 \%$. CSOs were re-interviewed at 3 and 6 months from their first session. At the 3-month follow-up, $97 \%$ of the CSOs were interviewed and at the 6-month follow-up, 95\% of the CSOs were interviewed.

Logistic regression was used separately to examine whether CSO ethnicity and relationship type with the IP were predictive of IP engagement in therapy, controlling for CSO report of IP severity at the time of CSO admission into the study. Entered at step 1 , severity of IP illicit drug use and alcohol consumption was characterized as the percent days completely abstinent in the 90 days prior to CSO recruitment. At step 2, a selected CSO characteristic was entered (indicator coded) and the chi-square improvement in model fit was evaluated. The criterion variable, engagement in therapy by an IP, was coded as yes (1) or no (0) in both logistic regressions.

CSO ethnicity (Hispanic and Anglo) was not predictive of whether an IP became engaged in Phase II therapy, $X^{2}$ improvement $=1.34(1), p<0.25$. Descriptively, about $80 \%(n=24)$ of Hispanic CSOs had IPs engaged in Phase II treatment whereas a slightly lower percentage of Anglo CSOs $(72.4 \%, n=21)$ had IPs who were engaged in treatment. Controlling for baseline severity of IP drug and alcohol use, IPs with parent CSOs were significantly more likely to engage in therapy than were IPs with non-parent CSOs, $X^{2}$ improvement $=6.17,(1), p<0.01$. Here, $83 \%$ (29 of 35) of the engaged IPs in the study had parent CSOs. In comparison, a majority of IPs with non-parent CSOs did not become engaged in therapy $(68.8 \%, n=11)$.

Of the 44 IPs who completed Phase II intake assessment (excluding two additional IPs who sought treatment at other facilities), 42 (95\%) returned to begin treatment. Of 12 
TABLE 2

CSO Functioning at Intake and 3- and 6-Month Follow-up for Total Sample and by Whether IP Became Engaged in Treatment

\begin{tabular}{lcccc}
\hline \multicolumn{1}{c}{ Variable } & Intake & 3 Months & 6 Months & $p$ \\
\hline Beck Depression Inventory & & & & \\
$\quad$ Total sample & $14.17(7.13)$ & $9.85(6.61)$ & $8.02(7.36)$ & 0.01 \\
IP engaged & $13.13(6.12)$ & $8.68(5.61)$ & $7.18(6.85)$ & 0.19 \\
IP not engaged & $18.10(9.47)$ & $14.30(8.41)$ & $11.20(8.69)$ & \\
STAXI: Behavior & & & & \\
$\quad$ Total sample & $54.48(7.89)$ & $50.16(18.16)$ & $46.77(19.25)$ & 0.01 \\
$\quad$ IP engaged & $55.35(7.16)$ & $51.98(15.32)$ & $49.41(16.81)$ & 0.15 \\
IP not engaged & $52.00(9.52)$ & $44.94(24.45)$ & $39.19(24.01)$ & \\
STAXI: State & & & & \\
Total sample & $14.67(5.52)$ & $11.18(5.42)$ & $9.79(4.87)$ & 0.01 \\
IP engaged & $14.85(5.73)$ & $11.11(4.52)$ & $10.54(4.59)$ & 0.41 \\
IP not engaged & $13.38(4.87)$ & $11.38(7.62)$ & $7.63(5.16)$ & \\
STAXI: Trait & & & & \\
$\quad$ Total sample & $17.55(4.95)$ & $14.79(6.26)$ & $14.15(6.41)$ & 0.01 \\
IP engaged & $17.54(4.48)$ & $15.20(5.81)$ & $14.72(5.83)$ & 0.20 \\
IP not engaged & $17.56(6.27)$ & $13.63(7.48)$ & $12.50(7.82)$ & \\
Medical Symptoms & & & & \\
$\quad$ Total sample & $0.87(1.03)$ & $0.68(0.94)$ & $0.63(1.03)$ & 0.01 \\
IP engaged & $0.80(0.93)$ & $0.72(0.96)$ & $0.72(1.09)$ & 0.15 \\
IP not engaged & $1.06(1.29)$ & $0.56(0.89)$ & $0.38(0.81)$ & \\
Physical Symptoms & & & & \\
$\quad$ Total sample & $5.16(3.14)$ & $4.08(2.30)$ & $3.50(2.95)$ & 0.01 \\
IP engaged & $5.16(3.14)$ & $3.73(2.74)$ & $3.35(2.84)$ & 0.83 \\
IP not engaged & $6.69(3.52)$ & $5.06(3.57)$ & $3.94(3.32)$ & \\
State/Trait Anxiety Inventory (STAI): State Anxiety & & & \\
$\quad$ Total sample & $49.02(16.55)$ & $38.27(17.32)$ & $35.00(16.53)$ & \\
IP engaged & $47.31(14.69)$ & $39.04(13.72)$ & $34.78(14.15)$ & 0.001 \\
IP not engaged & $54.13(20.95)$ & $35.93(13.72)$ & $35.67(22.85)$ & \\
State/Trait Anxiety Inventory (STAI): Trait Anxiety & & & \\
$\quad$ Total sample & $45.67(12.35)$ & $37.55(16.16)$ & $34.98(16.11)$ & 0.001 \\
IP engaged & $43.56(11.50)$ & $38.71(13.06)$ & $35.04(13.89)$ & \\
IP not engaged & $52.00(13.02)$ & $34.07(23.38)$ & $34.80(22.08)$ & \\
\hline & & & & \\
\end{tabular}

possible sessions, IPs on average completed 7.60 sessions $(63 \%, S D=4.58)$, with a median of 6 . Thirty-one percent $(n=13)$ of the IPs who attended at least one session completed all 12 therapy sessions, and 64\% completed at least five. IPs were seen for one follow-up, 3 months after their first treatment session. The 3-month follow-up rate for IPs was $95 \%$.

We asked whether the number of days between CSO recruitment and IP engagement was related to IP baseline motivation and the severity of illicit drug use or both. CSO reports of IP motivation at the time of CSO recruitment (three Stages of Change, Readiness, and Treatment Eagerness [SOCRATES] scales: Ambivalence, Problem Recognition, and Taking Steps) were not predictive of the speed with which an IP was engaged in therapy. Likewise, CSO report of IP severity was not significantly related with the number of days between recruitment and engagement, $(r=-0.23, p<0.15)$. Finally, neither the IP's own three motivation scales (largest obtained $r=-0.23, p<0.16$ ) nor the 
baseline severity of illicit drug use reported by IPs was predictive of the speed in which IPs entered treatment.

\section{CSO Functioning}

Table 2 provides the intake, 3- and 6-month values of eight measures depicting CSO functioning (labeled total sample). These measures are also displayed in Table 2 according to whether or not an IP became engaged in Phase II therapy. A multivariate repeated measures ANOVA with a single within-subject factor (three levels: intake, 3and 6-month follow-up) was used to determine whether CSO functioning changed in relation to entry into Phase I treatment. As shown, whether or not an IP became engaged in Phase II treatment, CSOs reported significant benefit from therapy on all seven measures. Showing significant gains during the 12 weeks of treatment in comparison to pretreatment levels, CSOs continued to maintain these improvements between the 3- and 6-month follow-up. As shown in Table 2, no differential benefit on any of the eight measures representing CSO functioning was reported by CSOs according to whether their IP was engaged in therapy.

\section{CSO and IP Relationship Functioning}

Three measures were used to evaluate potential changes in CSO-IP relationships. Each was collected at intake, 3- and 6-month follow-ups. The first measure was a single item from the Relationship Happiness Scale that asked about overall relationship happiness, and the remaining two measures were subscales from the Family Environment Scale (FES: Cohesion and Conflict). A multivariate approach to repeated measures was used separately for each of these measures, and the model consisted of one within-subject factor with three levels (intake, 3- and 6-month data points). Shown in Table 3, CSO report of relationship happiness increased somewhat during treatment, but the change did not exceed chance fluctuation. CSO report of family conflict decreased with time but, again, these changes were not significant. No discernable pattern in CSO reported family cohesion was found, $p<0.62$. IP self-report of CSO-IP relationship functioning was also compared at intake and 3-month follow-up, and means on the three measures are provided in Table 3. As shown, IPs reported a significant decline in the extent of conflict within their respective CSO relationships for the time between intake and 3-month follow-up interview. Likewise, IPs reported a significant increase in the extent of general happiness with CSO relationships during the time of IP therapy.

\section{IP Functioning}

Did IPs who engaged in Phase II therapy fare better than those IPs who did not enter treatment? Because non-engaged IPs did not provide self-report data in this study, examination of this question relied exclusively on CSO report of IP functioning. Several analyses were conducted therefore to ascertain the confidence we could place in the CSO report of IP functioning.

Convergence between CSO and IP reports of IP substance use was examined for those CSO-IP pairs engaged in Phase I and II therapy. In order to provide overlapping 
TABLE 3

CSO and IP Relationship Functioning at Intake and 3- and 6-Month Follow-ups

\begin{tabular}{lcccc}
\hline & Intake & 3 Months & 6 Months & $p$ \\
\hline CSO Report of: & & & & \\
$\quad$ General relationship happiness & $4.48(2.61)$ & $5.59(2.50)$ & $5.87(2.79)$ & 0.44 \\
FES: conflict & $3.21(2.26)$ & $2.75(2.04)$ & $2.77(2.34)$ & 0.21 \\
FES: cohesion & $4.90(2.35)$ & $4.82(2.78)$ & $4.57(2.94)$ & 0.62 \\
IP Report of: & & & & \\
$\quad$ General relationship happiness & $6.03(2.87)$ & $7.00(2.39)$ & - & 0.04 \\
FES: conflict & $3.27(2.37)$ & $2.27(2.42)$ & - & 0.01 \\
FES: cohesion & $5.18(2.50)$ & $5.09(2.63)$ & - & 0.83 \\
\hline
\end{tabular}

Note. $\quad$ FES $=$ Family Environment Scale.

TABLE 4

CSO Report of IP Severity at Time of CSO Recruitment into Study: Total Sample and by whether IP Became Subsequently Engaged in Therapy

\begin{tabular}{lllc}
\hline \multicolumn{1}{c}{ Variable } & $\begin{array}{c}\text { Total Sample } \\
(N=62)\end{array}$ & $\begin{array}{c}\text { Engaged } \\
(N=46)\end{array}$ & $\begin{array}{c}\text { Not Engaged } \\
(N=16)\end{array}$ \\
\hline $\begin{array}{l}\text { Past 90 Days } \\
\quad \text { Days incarceration }\end{array}$ & $1.56(6.43)$ & $0.64(3.06)$ & $4.13(11.33)$ \\
$\quad \begin{array}{l}\text { Days medical care } \\
\text { Lifetime }\end{array}$ & $1.26(3.51)$ & $1.02(2.56)$ & $1.94(5.46)$ \\
$\quad \begin{array}{l}\text { Number of lifetime incarcerations } \\
\text { Number of lifetime } \\
\text { alcohol/drug treatment }\end{array}$ & $2.62(4.57)$ & $2.70(4.55)$ & $2.38(4.94)$ \\
$\quad \begin{array}{l}\text { Number of lifetime } \\
\text { 12-step meetings }\end{array}$ & $2.56(11.09)$ & $3.24(12.97)$ & $0.81(1.11)$ \\
\hline
\end{tabular}

time frames to evaluate CSO and IP convergence, CSO report of IP substance use collected at 3-month follow-up was mapped against IP report of IP abstinence collected at Phase II intake. Significant and positive relationships were obtained between CSO and IP reports of IP percent days of abstinence from alcohol and illicit drugs $(r=0.44, p<$ $0.004)$ and days abstinence from illicit drugs only $(r=0.46, p<0.002)$, giving some confidence in CSO ability to report on IP functioning. It is noteworthy that the time frames for CSO and IP reports overlapped but were not identical, a factor likely to diminish convergence. Better convergence between CSO and IP pairs was obtained when we recoded CSO and IP report of IP abstinence dichotomously (abstinent/not abstinent). Here, based upon CSO 6-month report and IP 3-month report to allow for some reporting of abstinence, we found that $74 \%$ of the CSO-IP pairs $(n=28)$ were in agreement on the IP's abstinence or use, and in only two instances (5\%) did an IP report total abstinence when a CSO reported IP drug use.

Table 4 provides lifetime and past 90-day indices of IP functioning based upon CSO intake assessments. The number of lifetime treatment attempts, incarcerations, and lifetime 12-step attendance were chosen for analysis because these indices relate to IP treatment resistance and severity. In addition, the number of days of medical care and incarcerations in the 90-day assessment period are also reported. Measures of central tendency are 


\section{TABLE 5}

CSO Report of IP Functioning by IP Engagement Status

\begin{tabular}{lcccc}
\hline \multicolumn{1}{c}{ Variable } & Intake & 3 Months & 6 Months & $p$ Value \\
\hline \% Days Abstinent from Both Alcohol and Drugs & & & 0.02 \\
IP engaged & $0.31(0.36)$ & $0.47(0.37)$ & $0.44(0.41)$ & \\
IP not engaged & $0.20(0.30)$ & $0.21(0.29)$ & $0.17(0.34)$ & \\
\% Days Abstinent from Illicit Drug Use & & & \\
IP engaged & $0.38(0.38)$ & $0.53(0.38)$ & $0.51(0.42)$ & \\
IP not engaged & $0.25(0.34)$ & $0.34(0.38)$ & $0.20(0.36)$ & \\
Frequency of Negative Consequences & & & \\
IP engaged & $29.09(5.93)$ & $20.70(9.87)$ & $19.09(8.45)$ & \\
IP not engaged & $26.75(6.09)$ & $20.00(10.57)$ & $22.00(9.01)$ & \\
\% Days Paid for Work & & & \\
IP engaged & $0.27(0.30)$ & $0.33(0.33)$ & $0.37(0.33)$ & \\
IP not engaged & $0.34(0.33)$ & $0.29(0.37)$ & $0.35(0.32)$ & \\
\hline
\end{tabular}

provided for the total IP sample $(n=62)$ and divided by whether IPs became engaged in Phase II therapy. No mean differences between engaged and non-engaged IPs were found using independent $t$-tests for each of the measures.

Four measures were used to describe IP functioning at intake, 3- and 6-month follow-ups (CSO assessment points). Two measures described the percent days of abstinence of an IP in a given assessment period, differing only in the conservativeness of how the measure was computed. The first and more conservative, percent days abstinent from both alcohol and drugs, identified the percentage of days in an assessment interval that an IP was free of alcohol and any illicit drug use. The second measure, percent days abstinent from illicit drug use, indicated the percentage of days an IP was abstinent from the use of all illicit drugs, but did not count days of alcohol use as a violation of abstinence. The third and fourth measures depicting IP functioning were frequency of negative consequences surrounding illicit drug use in an assessment interval, and percentage of days paid for work during an assessment interval.

A multivariate approach to repeated measures was used to evaluate IP engagement status with one between-subject factor (engaged, not engaged) and a two level withinsubject factor (3- and 6-month CSO report of IP functioning). Baseline values of the within-subject factor were used as covariates in the four separate analyses. Table 5 provides the means $(S D)$ for the two IP engagement groups for intake, 3- and 6-month follow-ups. Probability values for rejection of the null hypothesis pertaining to the between-subject factor indicated that engaged IPs had significantly higher rates of abstinence than did non-engaged IPs throughout follow-up at months 3 and 6. This finding held for both the conservative measure including alcohol use as well as the abstinence measure pertaining to illicit drug use only. No differences, however, were found between engaged and non-engaged IPs on measures of adverse consequences nor on percent days paid for work. It may be the case that insufficient time had elapsed for differences on these measures to be detected. A 24-month follow-up of the sample is currently underway.

Because illicit drug use may be unobserved by CSOs, we conducted a second set of analyses examining IP-reported alcohol and drug use. For those IPs engaged in therapy, 
paired $t$ tests indicated significant improvement regardless of abstinence definitions: from both alcohol and illicit drugs, $t(39)=-2.02, p<0.05$, from illicit drugs but ignoring possible alcohol use, $t(39)=-3.63, p<0.001$, and allowing for alcohol and marijuana use, but not use of other illicit drugs, $t(39)=-4.78, p<0.001$. In agreement with CSO report, IP reports reflected no significant changes between intake and 3-month follow-up in the frequency of negative consequences surrounding illicit drug use, $p<0.24$, or in the percentage of days paid for work, $p<0.37$.

\section{An Illustrative Case}

To illustrate CRAFT procedures, we will briefly describe a case recruited via an advertisement in a local newspaper. The CSO was a 58-year old widow concerned about her 31-year old son who had a cocaine problem for 10 years. Her son was a large man: over six feet tall and 250 pounds. His last treatment had been 6 years prior, when he spent 30 days in an inpatient treatment center based on the Minnesota model. She explained that her son exhibited violent and erratic behavior and that he suffered from mood swings. She described her son as having a problem with anger and stated that "You don't want to get on his bad side". She reported that her son had attacked a counselor while in the inpatient treatment center, and consequently was discharged. She stated that her son stayed away from home for several days at a time and never discussed where he had been. She also stated that she had seen a white powder in his room on more than one occasion. She had made several attempts to convince her son to seek further treatment, but he had refused all of her efforts. Her stated goal was to help get her son some treatment for a long-standing problem of cocaine abuse. Upon the CSO entering Phase I treatment, the CRAFT therapist discussed strategies for how to approach her son about trying a "new treatment" program. Using a functional analysis format, therapy time was spent helping the CSO decide on a good time to approach her son. Once the CSO understood how and when to discuss entering treatment with her son and prepared to do so by using role-playing, it was suggested that she give it a try. After only three sessions, the CSO said that she now felt comfortable asking her son to accompany her to the next treatment session to learn about this new approach. At her fourth treatment session, the first author met with the son and discussed the program. Within $30 \mathrm{~min}$, the son agreed to "sample" CRA treatment, and subsequently completed all 12 treatment sessions. At the baseline assessment, the son reported using cocaine on $48 \%$ of the 90 days prior to treatment. At the 3-month follow-up visit, he reported using cocaine on only $2 \%$ of the 113 days since he began treatment. In addition to working on his drug use, much of his therapy was spent in creating social/ recreational outlets.

\section{DISCUSSION}

Project CRAFT was designed to help family members (CSOs) intervene with a drug abusing loved one (IP) who refused to seek treatment. The response to the CRAFT advertisement and other forms of recruitment was substantial. We received over 300 inquiries over a 13-month period. Out of these inquiries, $62 \mathrm{CSOs}$ met the criteria for inclusion into the study. These CSOs often had exhausted other community options in 
their efforts to help their loved one. They were highly motivated upon entering the treatment program and, on average, completed $87 \%$ of available treat-ment sessions.

Of primary interest was whether or not family members could change their own behaviors toward drug-dependent IPs to encourage them to seek treatment. From CSO report at intake, these IPs were considered resistant to change and had few inpatient, outpatient, or detoxification treatment experiences. Nevertheless, $74 \%$ of the CSOs in this project were able to encourage their IPs to seek treatment within 6 months either through Project CRAFT (71\%) or through other community services (3\%). Parents were more successful than other CSOs in engaging their loved one in treatment, and CRAFT was equally successful with Hispanic and non-Hispanic family members.

Although the CSO treatment focused on the drug use of their loved one, it was hypothesized that the CSOs would also show personal benefits from the CRAFT procedures. This hypothesis was clearly supported. CSOs improved their physical and emotional well-being during treatment and maintained those improvements after the completion of therapy. It is noteworthy that such improvements occurred in CSOs whether or not their IP eventually entered treatment. According to CSO report, improvement was not observed in the quality of relationship between the CSO and IP. However, IPs reported less conflict and increased general happiness in their relationship with their CSO over a 3-month period.

The IPs in this study were by definition unmotivated for treatment, at least from the perspective of a close significant other. It seems encouraging, therefore, that three fourths were engaged in treatment for drug abuse. Although engaging resistant drug users in treatment is itself encouraging, benefit is more likely if the IP remains in treatment long enough to learn the skills to remain free of drug use. Previous studies have reported rather discouraging retention rates. Agosti et al. (1991) followed 60 cocaine abusers who sought outpatient therapy. They found that over half $(55 \%)$ had dropped out of treatment by 4 weeks. Kleinman et al. (1991) studying crack and cocaine abusers seeking outpatient treatment, reported that $42 \%$ of individuals seen for an initial interview did not return for treatment and only $25 \%$ of individuals entering treatment remained in treatment for six or more sessions. In a large study of cocaine abusers, Hoffman et al. (1994) reported that $37 \%$ of their clients dropped out of therapy within the first week. In the present study, of the 44 IPs who sought treatment through the CRAFT project, 42 (95\%) returned for the first treatment session. These IPs completed an average of 7.6 treatment sessions out of a possible 12 sessions, with $28(64 \%)$ of the IPs completing five or more sessions. These results are particularly striking when compared with the Ellis et al. (1992) report that the modal treatment experience for individuals seeking substance abuse treatment in New Mexico was one visit.

More important than the favorable engagement and retention rates was the outcome following treatment. Over the 6-month follow-up period, engaged IPs (necessarily by CSO report) showed a significantly higher number of abstinent days when compared with IPs who did not enter treatment. This higher rate of abstinence held for alcohol, for marijuana, and for other illicit drug use. Neither IPs nor CSOs reported significant improvement in negative consequences related to drug use or percentage of days employed. 
An unanticipated finding was that CSOs who were parents were significantly more successful in engaging their resistant drug user to enter treatment than were non-parents. One possible reason for this is that parents tend not to "divorce" themselves from their children. Another possibility is that parents tend to be much less worried about possible retaliation through violence.

The present study included no control group, and so no firm conclusions can be drawn about the absolute efficacy of CRAFT in this application. In a parallel randomized trial focusing on alcohol abuse, we have found that CRAFT was significantly more effective in engaging IPs in treatment, as compared with Al-Anon and Johnson Institute approaches Miller et al. (in press). A randomized trial of CRAFT with CSOs of drug abusers is now underway at our Center.

\section{REFERENCES}

Abbott PJ, Weller SB, Delaney HD, Moore BA: Community reinforcement approach in the treatment of opiate addicts. Am J Drug Alcohol Abuse 24: 17-30, 1998.

Agosti V, Nunes E, Stewart JW, Quitkin FM: Patient factors related to early attrition from an outpatient cocaine research clinic: A preliminary report. Int J Addict 26: 327-334, 1991.

Al-Anon Faces Alcoholism, New York, Al-Anon Family Groups, 1984.

Azrin NH: Improvements in the community-reinforcement approach to alcoholism. Behav Res Ther 14: 339-348, 1976.

Azrin NH, Naster BJ, Jones R: Reciprocity counseling: A rapid learning based procedure for marital counseling. Behav Res Ther 11: 364-382, 1973.

Azrin NH, Sisson RW, Meyers R, Godley M: Alcoholism treatment by disulfiram and community reinforcement therapy. J Behav Ther Exp Psychiatry 13: 105-112, 1982.

Balster RL: Drug abuse potential evaluation in animals. Br J Addict 86: 1549-1558, 1991.

Bickel WK, De Grandpre RJ, Higgins ST, Hughes JR: Behavioral economics of drug self-administration: I Functional equivalence of response requirement and drug dose. Life Sci 47: 1501$1510,1990$.

Bickel WK, Hughes JR, De Grandpre RJ, Higgins ST, Rizzuto P: Behavioral economics of drug self-administration: IV. The effects of response requirement on the consumption of and interaction between concurrently available coffee and cigarettes. Psychopharmacology 107: 211216, 1992.

Bickel WK, De Grandpre RJ, Higgins ST, Hughes JR, Badger GJ: Effects of simulated employment and recreation on drug taking: A behavioral economic analysis. Exp Clin Psychopharmacol 3: 467-476, 1995.

Bien T, Miller WR, Tonigan JS: Brief interventions for alcohol problems: A review. Addiction 88: 315-336, 1993.

Brown JM, Miller WR: Impact of motivational interviewing on treatment participation and outcome. Psychol Addict Behav 7: 211-218, 1993.

Carroll M, Carmona GG, May SA: Modifying drug reinforced behavior by altering the economic conditions of the drug and nondrug reinforcer. J Exp Anal Behav 56: 361-376, 1991.

Constantini MF, Wermuth L, Sorensen JL, Lyons JS: Family functioning as a predictor of progress in substance abuse treatment. J Subst Abuse Treat 9: 331-335, 1992.

Dittrich JE, Trapold MA: A treatment program for the wives of alcoholics: An evaluation. Bull Soc Psychol Addict Behav 3: 91-102, 1984. 
Ellis BH, McCan I, Price G, Sewell CM: The New Mexico treatment outcome study: Evaluating the utility of existing information systems. J Health Care Poor Underserved 3: 138-150, 1992.

Foote FH, Szapocznik J, Kurtines WM, Perez-Vidal A, Hervis OK: One-person family therapy: A modality of brief strategic family therapy. In Progress in the Development of Cost-effective Treatment for Drug Abusers, edited by R. Ashery, Rockville, MD, NIDA, pp. 51-65, 1985.

Griffiths RR, Bigelow GE, Henningfield JE: Similarities in animal and human drug-taking behavior. Adv Subst Abuse 1: 1-90, 1980.

Higgins ST: Some potential contributions of reinforcement and consumer-demand theory to reducing cocaine use. Addict Behav 21: 803-816, 1996.

Higgins ST, Delaney DD, Budney AJ, Bickel WK, Hughes JR, Foerg F, Fenwick JW: A behavioral approach to achieving initial cocaine abstinence. Am J Psychiatry 148: 1218-1224, 1991.

Higgins ST, Budney AJ, Bickel WK: Applying behavioral concepts and principles to the treatment of cocaine dependence. Drug Alcohol Depend 34: 87-97, 1994.

Hoffman JA, Caudill BD, Koman JJ, Luckey JW, Flynn PM, Hubbard RL: Comparative cocaine abuse treatment strategies: Enhancing client retention and treatment exposure. $J$ Addict Dis 13: 115-128, 1994.

Hunt GM, Azrin NH: A community-reinforcement approach to alcoholism. Behav Res Ther 11: 91104, 1973.

Hursh SR: Behavioral economics of drug self-administration and drug policy. J Exp Anal Behav Special issue: Behavioral pharmacology 56: 377-394, 1991.

Institute of Medicine: Treating Drug Problems Vol. 1, Washington, DC, National Academy Press, 1990.

Johnson VE: Intervention: How to Help Those Who Don't Want Help, Minneapolis, MN, Johnson Institute, 1986.

Kaufman E: Family systems and family therapy of substance abuse: An overview of two decades of research and clinical experience. Int $J$ Addict 20: 897-916, 1985.

Kaufman E, Kaufman P, eds: Family Therapy of Drug and Alcohol Abuse, 2nd edition, Boston, MA, Allyn and Bacon, 1992.

Kazdin AE: Methodology, design, and evaluation in psychotherapy research. In Handbook of Psychotherapy and Behavior Change, 4th ed., edited by A.E. Bergin and Garfields, New York, John Wiley and Sons, pp. 19-71, 1994.

Kleinman PH, Woody GE, Todd TC, Millman RB, Kang SY, Kemp J, Lipton DS: Crack and cocaine abusers in outpatient psychotherapy. In Psychotherapy and Counseling in the Treatment of Drug Abuse, edited by L. Onken and J. Blaine, Rockville, MD, NIDA Research Monograph (104), pp. 24-35, 1990.

Liepman MR, Nirenberg TD, Begin AM: Evaluation of a program designed to help family and significant others to motivate resistant alcoholics into recovery. Am J Drug Alcohol Abuse 15: 209-221, 1989.

Mallams JH, Godley MD, Hall GM, Meyers RJ: Social-systems approach to resocializing alcoholics in the community. J Stud Alcohol 43: 1115-1123, 1982.

McCrady BS: Outcomes of family-involved alcoholism treatment. Recent Dev Alcohol 7: 165-182, 1989.

McLellan AT, Woody GE, Luborsky L, O'Brien CP, Druley KA: Increased effectiveness of substance abuse treatment: A prospective study of patient-treatment "matching". J Nerv Ment Dis 171: 597-605, 1983.

Meyers RJ, Dominguez TP, Smith JE: Community reinforcement training with concerned others. In Sourcebook of Psychological Treatment Manuals for Adult Disorders, edited by V. VanHasselt and M. Hersen, New York, Plenum, 1996.

Meyers RJ, Smith JE: Clinical Guide to Alcohol Treatment: The Community Reinforcement Approach, New York, Guildford Press, 1995. 
Meyers RJ, Smith JE: Getting off the fence: Procedures to engage treatment resistant drinkers. $J$ Subst Abuse Treat 14: 467-472, 1997.

Meyers RJ, Smith JE, Miller EJ: Working through the concerned significant other: Community reinforcement and family training. In Treating addictive behaviors: Processes of change, edited by W.R. Miller and N. Heather, 2nd edn., New York, NY, Plenum Press, 1998.

Miller BA: The interrelationships between alcohol and drugs and family violence. In Drugs and Violence: Causes, Correlates, and Consequences, edited by M. de la Rosa, E. Lambert and B. Gropper, Rockville, MD, National Institute on Drug Abuse, pp. 177-207, 1990.

Miller WR: Manual for Form 90: A Structured Assessment Interview for Drinking and Related Behaviors Vol. 5, Rockville, MD, NIAAA Project MATCH Monograph Series, 1996.

Miller WR, Hester RK: The effectiveness of alcoholism treatment: What research reveals. In Treating Addictive Behaviors, edited by W. Miller and N. Heather, New York, Plenum, 1986.

Miller WR, Kurtz E: Models of alcoholism used in treatment: Contrasting alcoholics anonymous and other models with which it is often confused. J Stud Alcohol 55: 159-166, 1994.

Miller WR, Sovereign RG, Krege B: Motivational interviewing with problem drinkers: II The drinker's check-up as a preventive intervention. Behav Psychother 16: 251-268, 1988.

Miller WR, Zweben A, DiClemente CC, Rychtarik RG: Motivational Enhancement Therapy Manual: A Clinical Research Guide for Therapists Treating Individuals with Alcohol Abuse and Dependence Vol. 2, edited by Margaret E. Mattson, Rockville, MD, National Institute on Alcohol Abuse and Alcoholism Project MATCH Monograph Series, 1992.

Miller WR, Benefield RG, Tonigan JS: Enhancing motivation for change in problem drinking: A controlled comparison of two therapist styles. J Consult Clin Psychol 61: 455-461, 1993.

Miller, WR, Meyers, RJ, Tonigan, JS: Engaging the unmotivated in treatment for alcohol problems: A comparison of three strategies for intervention through family members. $J$ Consult Clin Psychol, in press.

Moos RH, Finney JW, Cronkite RC: Alcoholism Treatment: Context, Process, and Outcome, New York, Oxford University Press, 1990.

O'Farrell TJ, ed: Treating Alcohol Problems: Marital and Family Interventions, New York, Guilford Press, 1993.

Patterson G: Coercive Family Process, Eugene, OR, Castalia, 1982.

Saunders B, Wilkinson C, Phillips M: The impact of a brief motivational intervention with opiate users attending a methadone programme. Addiction 90: 415-424, 1995.

Sisson RW, Azrin NH: Family-member involvement to initiate and promote treatment of problem drinkers. J Behav Ther Exp Psychiatry 17: 15-21, 1986.

Snow MG, Prochaska JO, Rossi JS: Stages of change for smoking cessation among former problem drinkers: A cross-sectional analysis. J Subst Abuse 4: 107-116, 1992.

Stanton MD, Todd TC: The Family Therapy of Drug Abuse and Addiction, New York, Guilford Press, 1982.

Stitzer ML, Kirby KC: Reducing illicit drug use among methadone patients. In Improving Drug Abuse Treatment, edited by R. Pickens, C. Leukefeld and C. Schuster, Rockville, MD, NIDA, pp. 178-203, 1991.

Stitzer ML, Bigelow GE, Liebson I: Reinforcement of drug abstinence: A behavioral approach to drug abuse treatment. In Behavioral Analysis and Treatment of Drug Abuse, edited by N. Krasnegor, Rockville, MD, NIDA, pp. 68-90, 1979.

Szapocznik J, Kurtines WM, Foote F, Perez-Vidal A, Hervis O: Conjoint versus one-person family therapy: Some evidence for the effectiveness of conducting family therapy through one person. J Consult Clin Psychol 51: 889-899, 1983.

Szapocznik J, Kurtines WM, Foote F, Perez-Vidal A, Hervis O: Conjoint versus one-person family therapy: Further evidence for the effectiveness of conducting family therapy through one person with drug-abusing adolescents. J Consult Clin Psychol 54: 395-397, 1986. 
Thomas E, Santa C: Unilateral family therapy for alcohol abuse: A working conception. Am J Fam Ther 10: 49-58, 1982.

Thomas E, Santa C, Bronson D, Oyserman D: Unilateral family therapy with spouses of alcoholics. $J$ Soc Serv Res 10: 145-163, 1987.

Thomas EJ, Adams KB, Yoshioka MR, Ager RD: Unilateral relationship enhancement in the treatment of spouses for uncooperative alcohol abusers. Am J Fam Ther 18: 334-344, 1990. 